\title{
Experts' Opinion on the Prenatal Therapy of Congenital Adrenal Hyperplasia (CAH) Due to 21-Hydroxylase Deficiency - Guideline of DGKED* in cooperation with DGGG (S1-Level, AWMF Registry No. 174/013, July 2015)
}

Adrenogenitales Syndrom mit 21-Hydroxylase-Defekt (AGS) - Stellungnahme zur pränatalen Therapie. Leitlinie der DGKED mit Beteiligung der DGGG (S1-Level, AWMF-Registernummer 174/013, Juli 2015)

Authors

Affiliations
H. G. Dörr ${ }^{1}$, G. Binder ${ }^{2}$, N. Reisch ${ }^{3}$, U. Gembruch ${ }^{4}$, P. G. Oppelt ${ }^{5}$, P. Wieacker ${ }^{6}$, J. Kratzsch ${ }^{7}$

The affiliations are listed at the end of the article.

\section{Key words \\ - CAH \\ - prenatal therapy \\ - dexamethasone \\ - off-label use \\ Schlüsselwörter \\ - AGS \\ - pränatale Therapie \\ - Dexamethason \\ - Off-Label-Use}

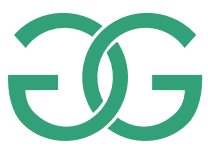

\section{DG:KED}

Deutsche Version unter: www.thieme-connect.de/ ejournals/gebfra

\section{Bibliography}

Dol http://dx.doi.org/

10.1055/s-0041-109717

Geburtsh Frauenheilk 2015; 75: 1232-1238 @ Georg Thieme Verlag KG Stuttgart · New York . ISSN 0016-5751

\section{Correspondence}

Prof. Dr. Helmuth G. Dörr

Kinder- und Jugendklinik

Universitätsklinikum

Erlangen-Nürnberg

Loschgestraße 15

91054 Erlangen

Helmuth-Guenther.Doerr@

uk-erlangen.de

\section{Abstract \\ V}

Purpose: This guideline of the German Society of Pediatric Endocrinology and Diabetology (DGKED) is designed to be experts' opinion on the current concept of prenatal therapy for congenital adrenal hyperplasia due to 21-hydroxylase deficiency (CAH). Several scientific medical societies have also participated in the guideline. It aims to offer guidance to physicians when they counsel affected families about prenatal therapy. Methods: The experts commissioned by the medical societies developed a consensus in an informal process. The consensus was subsequently confirmed by the steering committees of the respective medical societies.

Recommendations: Prenatal CAH therapy is an experimental therapy. We recommend designing and using standardized protocols for the prenatal diagnosis, therapy and long-term follow-up of women and children treated prenatally with dexamethasone. If long-term follow-up is not possible, then prenatal therapy should not be performed.

\section{Information on the Guideline}

\section{Guidelines program}

Information on the guidelines program is available at the end of the guideline.

\section{Citation format}

Experts' Opinion on the Prenatal Therapy of Congenital Adrenal Hyperplasia (CAH) Due to 21Hydroxylase Defiency - Guideline of DGKED in cooperation with DGGG (S1-Level, AWMF Registry No. 174/013, July 2015) Geburtsh Frauenheilk 2015; 75: 1232-1238

\section{Zusammenfassung \\ $\nabla$}

Ziel: Diese Leitlinie der Deutschen Gesellschaft für Kinderendokrinologie und -diabetologie (DGKED) e.V. unter Beteiligung mehrerer Fachgesellschaften wie der DGGG wurde als Stellungnahme von Experten zum derzeitigen Stand der pränatalen Therapie des Adrenogenitalen Syndroms mit 21-Hydroxylasedefekt konzipiert. Sie soll den beteiligten Ärzten als Orientierungshilfe bei der Entscheidung dienen, um betroffene Familien bei der pränatalen Therapie besser beraten zu können.

Methoden: Die von den beteiligten Fachgesellschaften beauftragten Experten entwickelten in einem informellen Prozess einen Konsensus. Anschließend wurde der Konsensus von den Vorständen der beteiligten Fachgesellschaften bestätigt. Empfehlungen: Die pränatale AGS-Therapie ist eine experimentelle Therapie. Für die pränatale Diagnostik und Therapie sollen standardisierte Protokolle entworfen und verwendet werden. Dies gilt auch für die Langzeitnachsorge der Frauen und Kinder, die pränatal mit Dexamethason behandelt wurden. Wenn die Langzeitnachsorge der Kinder nicht gewährleistet ist, dann soll auch keine pränatale Therapie durchgeführt werden. 
Table 1 Authors.

\begin{tabular}{ll}
$\begin{array}{l}\text { Author } \\
\text { Mandate holder } \\
\text { Coordinating lead guideline author }\end{array}$ & Medical society/organization/association \\
\hline $\begin{array}{l}\text { Prof. Dr. Helmuth-Günther Dörr } \\
\text { Other lead guideline authors }\end{array}$ & $\begin{array}{l}\text { German Society of Pediatric Endocrinology and Diabetology } \\
\text { (Deutsche Gesellschaft für Kinderendokrinologie und -diabetologie e. V. [DGKED]) }\end{array}$ \\
\hline Prof. Dr. Gerhard Binder & $\begin{array}{l}\text { German Society of Pediatric Endocrinology and Diabetology } \\
\text { (Deutsche Gesellschaft für Kinderendokrinologie und -diabetologie e. V. [DGKED]) }\end{array}$ \\
\hline PD Dr. Nicole Reisch & German Society of Endocrinology (Deutsche Gesellschaft für Endokrinologie e. V. [DGE]) \\
\hline Prof. Dr. Ulrich Gembruch & German Society of Gynecology and Obstetrics (Deutsche Gesellschaft für Gynäkologie und Geburtshilfe e. V. [DGGG]) \\
\hline PD Dr. Patricia G. Oppelt & Pediatric and Adolescent Gynecology Working Group (AG Kinder- und Jugendgynäkologie e. V.) \\
\hline Prof. Dr. Peter Wieacker & German Society of Human Genetics (Deutsche Gesellschaft für Humangenetik e. V. [GfH]) \\
\hline Prof. Dr. Jürgen Kratzsch & $\begin{array}{l}\text { German Society for Clinical Chemistry and Laboratory Medicine } \\
\text { (Deutsche Vereinte Gesellschaft für Klinische Chemie und Laboratoriumsmedizin [DGKL]) }\end{array}$ \\
\hline Guideline secretariat & $\begin{array}{l}\text { University Hospital for Pediatric and Adolescent Medicine, University of Ulm } \\
\text { (Universitätsklinik für Kinder- und Jugendmedizin, Universität Ulm) }\end{array}$ \\
\hline Dr. Anja Moß & \\
\hline
\end{tabular}

Authors

See $\odot$ Table 1.

\section{Abbreviations}

BW body weight

$\mathrm{CAH} \quad$ congenital adrenal hyperplasia

cffDNA cell-free fetal DNA

CVS chorionic villus sampling

DHEAS dehydroepiandrosterone sulfate

GW week of gestation

NIPT non-invasive prenatal testing

\section{Application of the Guideline}

\section{Purpose and objectives}

Prenatal therapy of CAH has been a treatment option in Germany for many years, although it remains an experimental treatment. The medical societies involved in this guideline have not previously released any official statements regulating this therapy or the follow-up of treated patients. Internationally, increasing numbers of comments have been published opposing this therapy. The aim of this guideline is to provide guidance to physicians when making decisions and to improve the counseling on prenatal therapy offered to affected families.

\section{Targeted areas of patient care}

Physicians working in private (outpatient) practice or in specialized hospitals.

\section{Target audience}

The target audience for this guideline are physicians working in the specialties such as genetics, gynecology, obstetrics, internal medicine and pediatric endocrinology.

Targeted patient group: planned pregnancy in families with one child with classic CAH (index case), heterozygous and homozygous carriers for classic $\mathrm{CAH}$, and compound heterozygous carriers for non-classic $\mathrm{CAH}$.

\section{Period of validity}

The validity of this guideline was confirmed by the boards/responsible persons of the participating medical societies/working groups/organizations/associations as well as by the board of the DGGG and the DGGG Guideline Commission in July 2015 and thereby approved in its entirety. This guideline is valid from July 1,2015 to July 1,2016 . The period of validity has been estimated based on the guideline's contents.

\section{Guideline \\ 1 Methodology}

The guideline was registered with AWMF on September 1, 2013. Professors Dörr and Binder compiled an initial draft of the guideline based on the consensus of the guideline group and sent the draft by e-mail to all persons involved. Drafts were circulated by e-mail between all authors and revised until the group reached a consensus.

\section{Use of existing guidelines on the same topic}

Existing guidelines AWMF Registry numbers 027/022, 027/047 and $078 / 015$ which contain material relevant to the topic under discussion were consulted during the compilation of this guideline.

\section{External review and adoption}

A version of the S1-guideline was placed online (on the homepage of DGKED) for public consultation for a period of 5 weeks (13.05.2014 - 16.06.2014) and the members of the involved medical societies were informed. Comments were collected and processed by the guideline group. Changes to the text of the guideline were done based on consensus. Everyone who sent in a comment was informed about the procedures used to process comments. The guideline group and the board of the DGKED approved the final version of the guideline in September 2014. This was followed by the final adoption of the guideline by the boards of the involved medical societies/organizations. During this procedure the board of Deutsche Gesellschaft für Kinder- und Jugendmedizin (DGKJ) withdrew its mandate and did not approve the final version of the guideline. Despite several discussions to 
clarify the issues, it proved impossible to obtain the approval of the DGKJ. The boards of the other 5 medical societies involved were then informed about the circumstances, and the importance and necessity of having an S1 recommendation for action in the current form was emphasized. The positive responses of the 5 other medical societies were filed with the secretariat of the DGKED by July 1, 2015. The final version of the guideline was submitted to AWMF on July 2, 2015.

\section{Introduction}

The authors are well aware that it is impossible to create an evidence-based guideline for a non-approved therapy. This S1guideline therefore represents an opinion; the guideline summarizes the current situation and offers recommendations for further action.

\section{Preamble}

Female neonates with classic congenital adrenal hyperplasia due to congenital deficiency of 21-hydroxylase (CAH) are usually born with intersex external genitalia. The therapy administered prenatally to treat $\mathrm{CAH}$ has the following aims: preventing the virilization of female fetuses with $\mathrm{CAH}$; preventing corrective genital surgery; and avoiding psychosocial stress for the family when their daughter is born with intersex genitalia. Complex genitoplasty procedures have their own surgery-related problems and are also associated with psychosocial stress for the affected patient and family.

As the differentiation of female genitalia starts in the 7th week after conception, therapy must be initiated immediately after establishing pregnancy. As no prenatal diagnosis is possible at this point in time, all pregnancies at risk for $\mathrm{CAH}$ are initially treated without knowing the diagnosis. The drug of choice is dexamethasone, which cannot be metabolized by the placenta and therefore achieves a maternal-fetal gradient of $1: 1$. Dexamethasone is administered immediately after the pregnancy has been established to women who have an increased risk of giving birth to a child with classic CAH. Therapy is only continued until the end of pregnancy if the prenatal diagnosis shows that the child is female and has classic CAH. In all other cases prenatal therapy is terminated.

The use of dexamethasone for the prenatal therapy of CAH is an off-label use. Nevertheless, this experimental therapy has been used all over the world for almost 30 years. The results published to date show that prenatal therapy - if it is administered correctly - can prevent virilization of the external genitalia in females [1-5]. The therapy is controversial because of the ethical dilemma (unaffected children are also treated) and because some data have shown that the therapy may have negative emotional and cognitive consequences. These data are from studies with small case numbers. Larger studies are therefore urgently required, along with follow-up examinations of all children treated prenatally, to determine or exclude possible side effects such as fetal programming from prenatal dexamethasone. The therapy requires the close cooperation of all involved physicians, particularly between prenatal medical centers and human genetics departments. Written parental consent is required after the physician has had an in-depth talk with the parents. Only gynecologists working closely with gynecology and/or internal endocrinology departments and certified prenatal medical centers can offer the appropriate care to the pregnant mother.

There is currently no standardized evidence-based protocol for the prenatal therapy of fetuses with CAH in Germany. The recom- mendations for prenatal therapy are based on empirical experience and data obtained from the literature. A careful and detailed documentation of the administered prenatal therapy should be a matter of course. In addition, it will be necessary to develop and implement protocols to follow-up children treated prenatally and their mothers.

\section{Definition and Basic Information}

(See also the guidelines with AWMF registry numbers 027/022, 027/047 and 078/015)

Classic congenital adrenal hyperplasia due to 21-hydroxylase deficiency (CYP21A2) is the most common disorder of cortisol biosynthesis in the adrenal cortex, with a prevalence of more than $90 \%$. The inheritance pattern for this disorder is autosomal recessive; the CYP21A2 gene is located on the short arm of chromosome 6 in the HLA III region in close proximity to a highly homologous pseudogene. Depending on the severity of the genetic defect and the extent of residual 21-hydroxylase activity, CAH occurs in one of 2 forms: classic CAH and non-classic $\mathrm{CAH}$ [6].

Female newborns with classic $\mathrm{CAH}$ present with intersex external genitalia (disorder of genital differentiation but normal female karyotype) at birth. Virilization of genitalia already starts in utero. The inner genitalia are always female, i.e. a uterus and ovaries are present. The severity of virilization is classified using the Prader scale and ranges from simple clitoral hypertrophy (Prader score 1) to complete fusion of the labioscrotal folds, an enlarged phallus-like clitoris, and extension of the urethra with a urethral opening in the glans penis (Prader score 5). Genital corrective surgery is often considered for girls with intersex genitalia (Prader score 3 and higher).

Female neonates born with non-classic $\mathrm{CAH}$ are unremarkable at delivery; while still prepubescent they may sometimes present with premature pubarche and/or acne. During puberty and after the conclusion of puberty girls with non-classic $\mathrm{CAH}$ are characterized by hyperandrogenemia, disorders of the menstrual cycle, and infertility.

\section{$5 \quad$ Diagnosis \\ 5.1 Prior to pregnancy}

Affected families usually have an index case (a previous child with $\mathrm{CAH}$ ). In rare cases parents may be known to be heterozygous without an index case. Detailed genetic counseling with genetic diagnosis of the index case and of the parents should be done prior to conception. An interdisciplinary consultation about the therapeutic options and the approach used in prenatal therapy should also be done prior to conception. Parents should be informed during a detailed consultation that in the case of autosomal recessive inheritance, both boys and girls have a 1 in 4 risk of developing $\mathrm{CAH}$. It follows from the above that as long as the sex of the child is still unknown, 7 of 8 fetuses will be treated unnecessarily, i.e., 3 girls who do not require treatment and 4 boys who do not require treatment, as boys with $\mathrm{CAH}$ do not require treatment. The family must be informed of the benefits and the possible downsides (potential side effects for the mother and child; experience in animals and humans, long-term risks) of prenatal therapy as well as the risks involved in prenatal diagnosis.

The parents must also be informed of the fact that there is currently no standardized protocol for this treatment. There are also no protocols in Germany for the long-term follow-up care of children treated prenatally (or of their mothers), and treatment in 
Germany is currently based on protocols and data from other countries such as Sweden and the USA $[1,7]$.

All forms of genetic testing and the isolation of fetal DNA from maternal blood are diagnostic tests which are subject to the relevant provisions of the German Genetic Diagnosis Act.

Possible combinations of factors where prenatal therapy should be considered:

1. Families with one affected child (index case) with classic $\mathrm{CAH}$ (CYP21A2).

2. Known parental heterozygosity for classic $\mathrm{CAH}$ (no index case). 3. New relationship of a parent of a child with classic CAH if the new partner is known to be a carrier for classic $\mathrm{CAH}$.

4. Homozygosity or compound heterozygosity for classic CAH of one parent when the other parent is a heterozygous gene carrier for classic $\mathrm{CAH}$.

Genetic counseling is more difficult if the potential parents have differing mutations and there is no index case in the family with compound heterozygosity for these mutations.

Example: The mother has a typical mutation for classic $\mathrm{CAH}$, while the father has a mutation for non-classic CAH (e.g. exon 7 Val281Leu). In this case the child could be compound heterozygous for $\mathrm{CAH}$. The phenotype generally follows the mutation associated with higher residual activity, in other words, non-classic $\mathrm{CAH}$. This means that in this family prenatal therapy is not indicated.

\subsection{Prenatal diagnosis}

The prenatal diagnosis of CAH is made based on an invasive procedure, typically chorionic villus sampling (CVS) performed approximately in the 11th week of gestation (GW). The child's sex is determined using genetic methods or chromosome analysis after cells are briefly cultured. In the event that testing finds a female karyotype, genetic testing is then used to investigate whether the expected child is homozygous/compound heterozygous or heterozygous or only has the wild-type allele. In principle, prenatal genetic diagnosis could be done as part of amniocentesis. But as amniocentesis is performed later in pregnancy (from the 14th GW), prenatal diagnosis using CVS is preferable as it ensures that the period of potentially unnecessary dexamethasone intake is as short as possible. The risk of miscarriage is $0.5-1 \%$ for amniocentesis and approximately $1 \%$ for chorionic villus sampling.

Recently, 2 independent studies showed that it is possible to determine the sex of the fetus using the SRY test [8] and that correct genotyping [9] using cell-free fetal DNA (cffDNA) from maternal blood was possible in pregnancies at risk for CAH. In the study by Tardy-Guidollet et al., the SRY test was positive from the 5th week of gestation ( 4 weeks +5 days). This avoided prenatal therapy with dexamethasone in $68 \%$ of male fetuses [8]. In the study by New et al., the earliest time of diagnosis was the 6th week of gestation; based on the results of the diagnostic procedure, prenatal therapy was initiated even prior to the 9th week [9].

Non-invasive fetal sex determination using cffDNA is not yet a routine diagnostic procedure in Germany, but it is offered as part of NIPT (non-invasive prenatal testing) from the 7th GW after the last menstrual cycle as the percentage of fetal DNA in the free DNA present in maternal blood should be high enough by that point (around 10\%). The result is usually available within one week after obtaining the blood sample $[10,11]$.

\section{Current Experimental Therapy}

There is currently no standardized therapy protocol approved by the respective medical societies in Germany. As sexual differentiation starts early, from the 7th week after conception, therapy was usually initiated immediately after establishing the pregnancy and without yet knowing the diagnosis.

The drug of choice is the glucocorticoid dexamethasone, which is not metabolized by the placenta and which therefore achieves a maternal-fetal gradient of $1: 1$ [12]. The recommended starting dose of dexamethasone (suggested dosage calculation formula: $20 \mu \mathrm{g} / \mathrm{kg}$ BW/day) is divided into 3 individual doses administered over a period of $24 \mathrm{~h}[13,14]$. This dosage was determined empirically; there are no controlled studies on the optimal dosage or duration of therapy.

Some studies have also reported achieving the same effect with low dexamethasone dosages [15]. The physician should therefore select the lowest maternal dexamethasone dose that will ensure suppression of the fetal adrenal cortex.

Therapy is only continued if the fetus is female and has classic $\mathrm{CAH}$. If the fetus is not a mutation carrier and is not heterozygous or male, then the current practice is to reduce the dexamethasone dose by $0.5 \mathrm{mg}$ every 2 nd day.

The care provided to a pregnant high-risk woman must be closely coordinated by her gynecologist with a prenatal medical and/or endocrinology center. To the best of our knowledge, the procedure followed up to now in Germany is as follows:

\section{During pregnancy}

Sampling of maternal serum (approx. $2 \mathrm{ml}$ ): determination of cortisol (to verify suppression of the maternal adrenal cortex) and determination of estriol (to verify suppression of the fetal adrenal cortex) at the start of therapy and then every 4 weeks until birth [16]. The Swedish PREDEX protocol measures DHEAS prior to initiating therapy (6th GW after the last menstrual cycle) and then every 4 weeks until the 36th GW and measures estriol in gestational weeks 16-36 [7]. High-risk pregnancies are continually monitored and parameters (e.g. blood pressure, weight changes, urine tests) are recorded.

\section{During birth and postpartum}

The dexamethasone dose administered to the mother is gradually reduced postpartum by $0.5 \mathrm{mg}$ every 2nd day. Contacting the pediatric endocrinologist is recommended to discuss further diagnostic procedures and therapies. It is not necessary to arrange for an immediate transfer of the neonate to a pediatric hospital.

\section{In the neonate}

Neonatal screening should be done on the 3rd day of life; in addition, venous blood samples should be collected to determine serum electrolyte levels, for blood gas analysis, and to determine 17-OHP, androstenedione and testosterone levels and renin concentrations. Hydrocortisone therapy should be initiated (12$15 \mathrm{mg} / \mathrm{m}^{2}$ body surface; e.g. 2-1- $1 \mathrm{mg} /$ day) together with Astonin $\mathrm{H}$ therapy $(0.1 \mathrm{mg}$ tablets; e.g. $1 / 2-1 / 4-1 / 2)$. Postnatal genetic confirmation of the prenatal diagnosis should be attempted (possibly through umbilical cord blood sampling).

\subsection{Maternal safety}

There are numerous studies on prenatal therapy [2,4,7,17-22]. The study group working with Maria New in New York has the most extensive experience [18,20,23-25]. Maternal side effects 
such as increased weight gain and/or striae and edema have been reported in individual cases; these effects were found to be reversible after dexamethasone was discontinued. Neither arterial hypertension nor diabetes mellitus were noted during dexamethasone therapy $[20,26]$.

In a survey done by questionnaire of dexamethasone-treated mothers in the USA $(n=22)$, almost all of them $(n=20)$ were positive about the benefits of prenatal therapy, stating that they would undergo dexamethasone treatment again in a subsequent pregnancy [27]. These results are in contrast to results reported from Sweden [28]. Only $70 \%$ of women $(n=23)$ surveyed by questionnaire were prepared to undergo prenatal therapy again in a subsequent pregnancy.

\subsection{Fetal and pediatric safety}

Length at birth, head circumference and birthweight were within normal ranges for all of the neonates who received prenatal therapy. To date, there have been no reports of malformations such as orofacial cleft. Postnatal growth of treated children was normal [26]. The long-term data, collected with the help of questionnaires sent to the parents ( 174 children treated prenatally compared with 313 untreated children, age range: 1 month to 12 years), showed no differences in cognitive, social or psychomotor development [29]. A follow-up study was done of 140 children aged between 5 and 12 years, 25 of whom were girls with CAH who had received prenatal treatment. The study showed that girls with CAH treated prenatally were less masculine in their behavior compared to girls with $\mathrm{CAH}$ who did not receive prenatal therapy [30]. Using standardized neuropsychological tests, Hirvikoski et al. found deficits in verbal working memory in children with CAH treated prenatally [31]. A meta-analysis of studies published to date found no significant differences in the behavior of prenatally treated children [32]. A follow-up of female patients with CAH treated prenatally $(n=8)$ found a trend to cognitive deficits compared to a control group $(n=15)$, but the difference was not statistically significant [33]. One study group in Warsaw also subsequently carried out neuropsychological examinations of a small number of girls treated prenatally ( 9 with CAH vs. 8 without $\mathrm{CAH}$ ) and found that the girls with $\mathrm{CAH}$ treated prenatally performed better in all cognitive tests [34].

\subsection{Dexamethasone in animal experiments}

Malformations such as orofacial clefts, pulmonary hypoplasia and anencephalus have been reported in experiments on animals treated with dexamethasone [22]. Fatty degeneration of the liver (rats, sheep, primates) and changes in glomerular filtration rates have also been noted [35]. There are also reports of disorders of brain development and behavioral changes in treated animals [36]. Adult rodents had arterial hypertension and hyperglycemia with increased insulin concentrations after prenatal glucocorticoid therapy $[37,38]$. The offspring of non-human primates treated during pregnancy with high doses of dexamethasone (120 or $200 \mu \mathrm{g} / \mathrm{kg}$ BW per day) had increased cortisol levels after experiencing only mild stress as well as hypertension at the age of 12 months [39].

\subsection{Documentation of prenatal therapy in Germany} Already in 1990, the working group/section for pediatric endocrinology (Arbeitsgemeinschaft/Sektion für Pädiatrische Endokrinologie [APE/SPE]) proposed that cases known to pediatric endocrinologists should be recorded in a central registry (Hospital for
Children and Adolescents of Erlangen University, Prof. Dr. H.-G. Dörr). There was no plan to provide financial support for the project. A questionnaire was developed and initially sent to all pediatric endocrinologists based on the assumption that families (with an index case) would inform their pediatric endocrinologist of future pregnancies. The questionnaire was recently revised; one version was developed for the affected mother/family and another version was developed for the treating physician; the physicians' version should be completed by the treating gynecologist. The questionnaires can be obtained from the homepages of DGKED (www.paediatrische-endokrinologie.de) and the German CAH self-help group (https://www.ags-initiative.de/) or are available on request.

Questionnaires are completed on a voluntary basis. It has not been possible to carry out any detailed analysis of the documented data in Germany as the questionnaires have either not been completed at all or were returned incomplete.

\section{$7 \quad$ Conclusion and Prospects}

Prenatal CAH therapy is still an experimental therapy. The experience to date has shown that prenatal therapy is effective. Female neonates with CAH who received prenatal therapy had externally unremarkable genitalia or genitalia with only mild virilization (Prader score 1). No serious maternal complications have been recorded; no malformations were reported for any of the neonates [40]. Up to now, the ethical dilemma was that 7 of 8 fetuses ( 4 males and 3 females) were treated unnecessarily with dexamethasone. With new procedures for prenatal diagnosis based on an analysis of cell-free DNA obtained from maternal blood samples it will be possible in future to offer targeted therapy which will only treat female fetuses or even only homozygous or compound heterozygous female fetuses with CAH.

The data on the potential negative emotional and cognitive effects on children with $\mathrm{CAH}$ who received prenatal treatment must be taken seriously. However, these data are from studies with small case numbers. Larger studies and follow-up studies of all children treated prenatally are therefore urgently needed to establish or exclude side effects such as fetal programming from prenatal dexamethasone. Standardized protocols for prenatal diagnosis and therapy should be developed and implemented. This also applies to the long-term follow-up of women and children treated prenatally with dexamethasone. If long-term follow-up of the children cannot be guaranteed, then they should not be treated prenatally.

All prenatal CAH therapies should be documented and recorded in a central registry. The registry should also include those pregnancies where therapy was terminated early after receiving the results of the prenatal diagnostic procedure [6].

The medical societies involved should agree on a protocol for therapy and follow-up which should then be assessed and confirmed by an ethics committee.

\footnotetext{
Affiliations

${ }^{1}$ Kinder- und Jugendklinik des Universitätsklinikums Erlangen, Erlangen

2 Univ.-Kinderklinik Tübingen, Sektion Endokrinologie, Tübingen

${ }^{3}$ Medizinische Klinik und Poliklinik IV. Klinikum der Universität München, München

${ }^{4}$ Abteilung für Geburtshilfe und Pränatalmedizin der Universität Bonn, Bonn

${ }^{5}$ Kinder- und Jugendgynäkologie, Frauenklinik des Universitätsklinikums Erlangen, Erlangen

${ }^{6}$ Institut für Humangenetik, Universitätsklinikum Münster, Münster

${ }^{7}$ Institut für Laboratoriumsmedizin, Klinische Chemie und Molekulare

Diagnostik der Universität Leipzig, Leipzig
} 


\section{References}

1 New MI. Prenatal treatment of congenital adrenal hyperplasia. The United States experience. Endocrinol Metab Clin North Am 2001; 30: 1-13

2 Forest MG, Betuel H, David M. Prenatal treatment in congenital adrenal hyperplasia due to 21-hydroxylase deficiency: up-date 88 of the French multicentric study. Endocr Res 1989; 15: 277-301

3 Forest MG, Dörr HG; on behalf of ESPE. Prenatal therapy in congenital adrenal hyperplasia due to 21-hydroxylase-deficiency: retrospective follow-up study of 253 treated pregnancies in 215 families. Endocrinologist 2003; 13: 252-259

4 New MI, Carlson A, Obeid J et al. Prenatal diagnosis for congenital adrenal hyperplasia in 532 pregnancies. J Clin Endocrinol Metab 2001; 86: 5651-5657

5 Wudy SA, Homoki J, Teller WM. Successful prenatal treatment of congenital adrenal hyperplasia due to 21-hydroxylase deficiency. Eur J Pediatr 1994; 153: 556-559

6 Speiser PW, Azziz R, Baskin LS et al. A summary of the Endocrine Society clinical practice guidelines on congenital adrenal hyperplasia due to steroid 21-hydroxylase deficiency. Int J Pediatr Endocrinol 2010; 2010: 494173

7 Lajic S, Nordenstrom A, Ritzen EM et al. Prenatal treatment of congenital adrenal hyperplasia. Eur J Endocrinol 2004; 151 (Suppl. 3): U63-U69

8 Tardy-Guidollet V, Menassa R, Costa JM et al. New management strategy of pregnancies at risk of congenital adrenal hyperplasia using fetal sex determination in maternal serum: French cohort of 258 cases (2002-2011). J Clin Endocrinol Metab 2014; 99: 1180-1188

9 New MI, Tong YK, Yuen T et al. Noninvasive prenatal diagnosis of congenital adrenal hyperplasia using cell-free fetal DNA in maternal plasma. J Clin Endocrinol Metab 2014; 99: E1022-E1030

10 Avent ND, Chitty LS. Non-invasive diagnosis of fetal sex; utilisation of free fetal DNA in maternal plasma and ultrasound. Prenat Diagn 2006; 26: 598-603

11 Meaney C, Norbury G. Non-invasive prenatal diagnosis. Methods Mol Biol 2011; 688: 155-172

12 Beck JC, Johnson JW. Maternal administration of glucocorticoids. Clin Obstet Gynecol 1980; 23: 93-113

13 Speiser PW. Prenatal treatment of congenital adrenal hyperplasia. J Urol 1999; 162: 534-536

14 Claahsen-van der Grinten HL, Stikkelbroeck NM, Otten BJ et al. Congenital adrenal hyperplasia-pharmacologic interventions from the prenatal phase to adulthood. Pharmacol Ther 2011; 132: 1-14

15 Coleman MA, Honour JW. Reduced maternal dexamethasone dosage for the prenatal treatment of congenital adrenal hyperplasia. BJOG 2004; 111: 176-178

16 Dörr HG, Sippell WG, Willig RP. [Prenatal diagnosis and therapy of adrenogenital syndrome with 21-hydroxylase deficiency]. Geburtsh Frauenheilk 1992; 52: 586-588

17 Forest MG, David M. Prenatal treatment of congenital adrenal hyperplasia due to 21-hydroxylase deficiency: a 10 year experience. Indian J Pediatr 1992; 59: 515-522

18 New MI. Vindication of prenatal diagnosis and treatment of congenital adrenal hyperplasia with low-dose dexamethasone. Am J Bioeth 2010; 10: 67-68

19 Nimkarn S, New MI. Prenatal diagnosis and treatment of congenital adrenal hyperplasia owing to 21-hydroxylase deficiency. Nat Clin Pract Endocrinol Metab 2007; 3 : 405-413

20 Nimkarn S, New MI. Congenital adrenal hyperplasia due to 21-hydroxylase deficiency: a paradigm for prenatal diagnosis and treatment. Ann N Y Acad Sci 2010; 1192: 5-11

21 Hirvikoski T, Nordenstrom A, Wedell A et al. Prenatal dexamethasone treatment of children at risk for congenital adrenal hyperplasia: the Swedish experience and standpoint. J Clin Endocrinol Metab 2012; 97: $1881-1883$
22 Miller WL, Witchel SF. Prenatal treatment of congenital adrenal hyperplasia: risks outweigh benefits. Am J Obstet Gynecol 2013; 208: 354359

23 Mercado AB, Wilson RC, Cheng KC et al. Prenatal treatment and diagnosis of congenital adrenal hyperplasia owing to steroid 21-hydroxylase deficiency. J Clin Endocrinol Metab 1995; 80: 2014-2020

24 New MI. Prenatal treatment of congenital adrenal hyperplasia: author differs with technical report. Pediatrics 2001; 107: 804

25 New MI, Abraham M, Yuen T et al. An update on prenatal diagnosis and treatment of congenital adrenal hyperplasia. Semin Reprod Med 2012; 30: 396-399

26 Lajic S, Nordenstrom A, Hirvikoski T. Long-term outcome of prenatal treatment of congenital adrenal hyperplasia. Endocr Dev 2008; 13: 82-98

27 Trautman PD, Meyer-Bahlburg HF, Postelnek J et al. Mothers' reactions to prenatal diagnostic procedures and dexamethasone treatment of congenital adrenal hyperplasia. J Psychosom Obstet Gynaecol 1996; 17: $175-181$

28 Lajic S, Wedell A, Bui TH et al. Long-term somatic follow-up of prenatally treated children with congenital adrenal hyperplasia. J Clin Endocrinol Metab 1998; 83: 3872-3880

29 Meyer-Bahlburg HF, Dolezal C, Baker SW et al. Cognitive and motor development of children with and without congenital adrenal hyperplasia after early-prenatal dexamethasone. J Clin Endocrinol Metab 2004; 89: $610-614$

30 Meyer-Bahlburg HF, Dolezal C, Baker SW et al. Prenatal androgenization affects gender-related behavior but not gender identity in 5-12-yearold girls with congenital adrenal hyperplasia. Arch Sex Behav 2004; 33: $97-104$

31 Hirvikoski T, Nordenstrom A, Lindholm T et al. Cognitive functions in children at risk for congenital adrenal hyperplasia treated prenatally with dexamethasone. J Clin Endocrinol Metab 2007; 92: 542-548

32 Merce Fernandez-Balsells M, Muthusamy K, Smushkin G et al. Prenatal dexamethasone use for the prevention of virilization in pregnancies at risk for classical congenital adrenal hyperplasia because of 21-hydroxylase (CYP21A2) deficiency: a systematic review and meta-analyses. Clin Endocrinol (Oxf) 2010; 73: 436-444

33 Meyer-Bahlburg HF, Dolezal C, Haggerty R et al. Cognitive outcome of offspring from dexamethasone-treated pregnancies at risk for congenital adrenal hyperplasia due to 21-hydroxylase deficiency. Eur J Endocrinol 2012; 167: 103-110

34 Maryniak A, Ginalska-Malinowska M, Bielawska A et al. Cognitive and social function in girls with congenital adrenal hyperplasia - Influence of prenatally administered dexamethasone. Child Neuropsychol 2014; 20: $60-70$

35 Khulan B, Drake AJ. Glucocorticoids as mediators of developmental programming effects. Best Pract Res Clin Endocrinol Metab 2012; 26: 689-700

36 National Council on Nutrition and Physical Activity in Norway. Extract from the Norwegian National Report on Physical Activity and Health. Scand J Med Sci Sports 2001; 11: 255-257

37 Seckl JR. Glucocorticoid programming of the fetus; adult phenotypes and molecular mechanisms. Mol Cell Endocrinol 2001; 185: 61-71

38 Seckl JR, Miller WL. How safe is long-term prenatal glucocorticoid treatment? JAMA 1997; 277: 1077-1079

39 de Vries A, Holmes MC, Heijnis A et al. Prenatal dexamethasone exposure induces changes in nonhuman primate offspring cardiometabolic and hypothalamic-pituitary-adrenal axis function. J Clin Invest 2007; 117: $1058-1067$

40 Vos AA, Bruinse HW. Congenital adrenal hyperplasia: do the benefits of prenatal treatment defeat the risks? Obstet Gynecol Surv 2010; 65: 196-205 


\section{Guideline Program}

\section{Editors}

Leading Professional Medical Associations

\section{OTs}

German Society of Gynecology and Obstetrics (Deutsche Gesellschaft für Gynäkologie und Geburtshilfe e. V. [DGGG])

Head Office of DGGG and Professional Societies Hausvogteiplatz 12

DE-10117 Berlin

info@dggg.de

http://www.dggg.de/

\section{President of DGGG}

Prof. Dr. med. Diethelm Wallwiener

Universitätsfrauenklinik Tübingen

Calwerstraße 7

DE-72076 Tübingen

DGGG Guidelines Representative

Prof. Dr. med. Matthias W. Beckmann

Universitätsklinikum Erlangen

Frauenklinik

Universitätsstraße 21-23

DE-91054 Erlangen

\section{Guidelines Coordination}

Dr. med. Paul Gaß, Tobias Brodkorb, Marion Gebhardt Universitätsklinikum Erlangen

Frauenklinik

Universitätsstraße 21-23

DE-91054 Erlangen

fk-dggg-leitlinien@uk-erlangen.de

http://www.dggg.de/leitlinienstellungnahmen

\section{OEGGG}

Austrian Society of Gynecology and Obstetrics (Österreichische Gesellschaft für Gynäkologie und Geburtshilfe [OEGGG])

Innrain 66A

AT-6020 Innsbruck

stephanie.leutgeb@oeggg.at

http://www.oeggg.at

President of OEGGG

Prof. Dr. med. Uwe Lang

Universitätsklinik für Frauenheilkunde und Geburtshilfe Graz

Auenbruggerplatz 14

AT-8036 Graz

OEGGG Guidelines Representative

Prof. Dr. med. Karl Tamussino

Universitätsklinik für Frauenheilkunde

und Geburtshilfe Graz

Auenbruggerplatz 14

AT-8036 Graz

\section{gynécologie}

suisse

Swiss Society of Gynecology and Obstetrics (Schweizerische Gesellschaft für Gynäkologie und Geburtshilfe [SGGG])

Gynécologie Suisse SGGG

Altenbergstraße 29

Postfach 6

CH-3000 Bern 8

sekretariat@sggg.ch

http://www.sggg.ch/

President of SGGG

Dr. med. David Ehm

FMH für Geburtshilfe und Gynäkologie

Nägeligasse 13

CH-3011 Bern

SGGG Guidelines Representative

Prof. Dr. med. Daniel Surbek

Universitätsklinik für Frauenheilkunde

Geburtshilfe und feto-maternale Medizin

Inselspital Bern

Effingerstraße 102

CH-3010 Bern 